\title{
Diáspora e Identidade na Contemporaneidade: considerações sobre as populações árabe e muçulmana e a formação de uma comunidade em Florianópolis/SC
}

\section{Diaspora and Identity in the Contemporary: consideration on the arabic and muslim population and the formation of a community in} Florianopolis/SC

Carolina Ferreira de Figueiredo*

Thamirys Mendes Lunardi***

Resumo: Este artigo visa abordar a temática da imigração e a construção de identidades a partir do contingente populacional estrangeiro de Florianópolis/SC, com o recorte temporal a partir da segunda metade do século $\mathrm{XX}$, especificamente àquele dito e auto-reconhecido como 'árabe' e outro definido como muçulmano. É primordial neste estudo estabelecer relações de aproximação e distanciamento entre esses termos e como estes se manifestam na cultura e nas relações sociais na capital catarinense. Assim, a pesquisa busca traçar mudanças no processo migratório, como condições, justificativas, proveniência e religiosidade, e, porquanto, na própria transformação da comunidade árabe estabelecida em Florianópolis, e no crescimento da comunidade muçulmana nas últimas décadas, tanto de origem árabe quanto nãoárabe. Ainda, a partir da análise de processos de deslocamento, identificando sentidos de pertencimento às comunidades, será enfoque a análise das últimas décadas do século XXI, onde o elemento "refugiado" parece central para a compreensão da cidade no tempo presente.

Palavras-chave: Imigração; Comunidade Árabe e Muçulmana; Florianópolis/SC.

Abstract: This paper aims to address the issue of immigration and the construction of identities of foreign populations in Florianópolis / SC. Starting at the second half of the twentieth century, focusing on the populations self-recognized as 'Arab' and other defined as Muslim. It is essential in this paper to establish close relations and distance between these terms and how they manifest themselves in the culture and

\footnotetext{
* Mestra em História pela Universidade Federal do Rio Grande do Sul (UFRGS).

** Mestra em Relações Internacionais pela Universidade Federal de Santa Catarina (UFSC).
} 
social relations in the capital of Santa Catarina. Thus, the research seeks to track changes in the migration process, as conditions, justifications, origins, and religion. The characteristics are in the core of the transformation of the Arab community established in Florianópolis, and the growth of the Muslim community in recent decades, both of Arab origin and not -Arabic. Thereofre, from the analysis of displacement processes, identifying belonging senses communities, this paper will focus on the analysis of the last decades of the century, where the "refugee" element seems central to understanding the city in the contemporary.

Keywords: Immigration; Muslim and Arab Community; Florianopolis/SC.

\section{Introdução}

A temática da imigração e suas transversalidades compreendem um estudo relevante no contemporâneo, uma vez que transitam entre passado, presente e futuro. Para o Brasil, especificamente, a análise histórica da formação do país através dos mais diversos processos migratórios é fundamental para se compreender realidades atuais; no aspecto global, a facilidade de trânsito, e mais recentemente, a necessidade de refúgio devido à guerras, ambientam uma transformação mundial, que no tocante do encontro com o outro, denota a necessidade de se compreender a alteridade, tanto pelo viés do reconhecimento individual e coletivo, quanto para a viabilização de políticas públicas institucionais dos países.

A identidade, ou as múltiplas identidades, então, tornam-se o fio condutor deste artigo, que pretende tecer algumas considerações acerca da comunidade árabe e muçulmana em Florianópolis no tempo presente, especialmente a partir da segunda metade do século XX e as primeiras décadas do século XXI. Essa população, não unívoca, modificou-se ao longo do tempo, alterando sujeitos migrantes, gênero, idade, atividade profissional, razões para migrar ${ }^{1}$, e estes dados mostram-se

\footnotetext{
${ }^{1}$ Estas questões foram aprofundadas a partir de um projeto de pesquisa desenvolvido na Universidade do Estados de Santa Catarina (UDESC) entre 2009 e 2011. A pesquisa intitulada Estrangeiros numa Ilha: populações estrangeiras na Ilha de Santa Catarina (1990-2010), teve como coordenador o professor Dr. Emerson César de Campos (UDESC) e na época os/as graduandos/as e bolsistas Bruno Bortoli, AUTORA, Catarina Lisboa do Carmo e AUTORA. Como um dos resultados de pesquisa, foi possível perceber diferenças marcantes no processo de migratório, a qual foi cunhado de "ondas", uma divisão artificial, porém relevante pois permitiu a análise dos processos circunscritos, bem como a
} 
relevantes para compreendermos como foi formada uma comunidade árabe dentro de Florianópolis, e em quais momentos o pertencimento "árabe" se funde (ou não) com o "muçulmano". Nesse sentido, é importante diferenciar os termos, ainda que as denominações de "árabe" e "muçulmano" estejam historicamente relacionadas. É dito "árabe" sujeitos que pertencem a uma série de códigos comuns, como língua, costumes e práticas sociais. É dito "muçulmano" sujeitos que praticam a religião Islâmica, seguindo os preceitos do Alcorão, que teria sido revelado para Mohamed (Maomé) pelo Deus Allah. Hoje em dia, por exemplo, há mais muçulmanos na Índia, que não são (necessariamente) culturalmente ligados ao elemento "árabe", do que no Oriente Médio propriamente. Ainda assim, para o estudo da comunidade árabe em Florianópolis, é interessante perceber as nuances, aproximações e distanciamentos destas duas denominações, como aborda Correia (2010), por exemplo, ao afirmar que na Mesquita, para a reza de sexta-feira "[...] Aqueles que conhecem o árabe podem acompanhar a leitura do Alcorão, sem necessitar da tradução para o português. Ou seja, o acesso ao material das oraçooes em árabe constitui elemento marcador de um maior pertencimento ao grupo" (p. 26). Estas e outras questões serão aprofundadas ao longo do artigo.

Historiograficamente, poucos registros acerca de populações árabes e muçulmanas foram realizados no estado de Santa Catarina, sendo que estes ainda devem ser problematizados. Devido ao numeroso deslocamento de italianos e alemães para o Estado no século XIX, e principalmente a partir de intenções em criar uma região europeizada, identificadas culturalmente como produtivos e portadores de progresso (SEYFERTH, 2008; KLUG, 1994; PIAZZA, 1982), a região construiu-se e carrega até hoje o ideal de ser "um pedacinho da Europa no país", o que acarreta, entre outros elementos, na invisibilização de diversos grupos populacionais, como o caso dos árabes. A produção intelectual em Santa Catarina segue de um modo geral esta linha, em que autores considerados como clássicos da historiografia, ao estudarem a população do estado, apresentam dados e relatos que focam principalmente na imigração europeia. Apesar desta constatação, que deve ser compreendida dentro de uma historicidade, teóricos abordaram a presença dos árabes, ainda que em pequenas extensões. Por exemplo, no livro "Santa Catarina: história da gente", Walter Piazza e Laura Hübener (2003), ocupam algumas poucas 
páginas ao informar sobre as áreas ocupadas pelos árabes no estado catarinense, apontando para as principais cidades onde cresceram comunidades. Oswaldo Rodrigues Cabral (1979), no livro "Nossa Senhora do Desterro", menciona a presença de árabes no comércio de Desterro, antigo nome de Florianópolis, podendo-se notar a existência desse grupo na cidade a partir da segunda metade do século XIX. Por último, no livro coordenado por Osvaldo Ferreira de Melo (1991), intitulado "História Sócio-Cultural de Florianópolis”, há um capítulo dedicado a presença árabe, escrito por José Felipe Boabaid. Neste estudo, apesar de poucos dados captados, há maiores menções sobre a cultura árabe na região, principalmente porque Boabaid, um descendente e inserido na comunidade, traz informações como os sobrenomes das famílias dos imigrantes.

Mais recentemente, têm sido produzidos no espaço da Universidade, Trabalhos de Conclusão de Cursos, Dissertações de Mestrado e Teses de Doutorado, nas áreas da Antropologia, História e Ciências Sociais, e que representam valiosos materiais para o desenvolvimento da presente pesquisa. A pesquisadora Liliane Carvalho (2002) estudou os imigrantes descendentes e sírios e libaneses na capital catarinense, apresentados em sua dissertação intitulada "Do Balcão à mesa: Imigrantes de descendentes de sírios e libaneses na construção de uma identidade na Grande Florianópolis (1910-1950)”. Claudia Voigt Espínola (2005) realizou uma etnografia com mulheres árabes muçulmanas, desenvolvida em sua tese "O véu que (des)cobre: etnografia da comunidade árabe muçulmana em Florianópolis”. Em 2008, Gabriel Soares realizou um Trabalho de Conclusão de Curso com foco na população palestina em Florianópolis, intitulada "Da Palestina ao Brasil: Identidade e imigração palestina em Florianópolis (1967-2007)”. E a já citada Mariana Knierim Correia (2010), com trabalho intitulado "Entre este e aquele: as uniões matrimoniais entre os muçulmanos residentes em Florianópolis- SC".

Ainda, é importante ressaltar que, uma vez que esta pesquisa tem como problemática central a imigração e os sujeitos envolvidos nesse processo, conceitos como o de identidade(s) e identificações, diáspora e nação são fundamentais para o desenvolvimento deste estudo. As identidades, amparadas pelos estudos de Homi Bhabha (2008) e Stuart Hall (2009), são compreendidas em sua forma múltipla, móvel e criativa, de modo a atrelá-las ao pertencimento, este também moldado à experiência e à cultura dos sujeitos. Como um sujeito diaspórico, Bhabha (1998) 
preocupa-se em entender a condição do estrangeiro e das relações étnicas no período pós-colonial. Para ele, a diferença cultural não é colocada em uma medida ontológica mas nas hifenações hídridas, no que o autor chama de "pedaços teimosos", que se relacionam a partir de negociações do estado formativo - recriado - das identidades. Essas hifenações constituem-se em um movimento em "em direção a um encontro com o processo ambivalente de cisão e hibridização que marca a identificação com a diferença da cultura" (BHABHA, 1998, p. 308). Em se pensando especificamente o processo de imigração da comunidade árabe e muçulmana de Florianópolis, a diáspora é uma possibilidade de movimentação das culturas, alterando os sentidos identitários e os locais, dimensão aprofundada por Stuart Hall (2009). Atrelando esses conceitos ao de nação, considera-se relevante o conceito de "comunidades imaginadas" de Benedict Anderson (2005), compreendendo que os elementos que identificam sujeitos são fabricados, e nesse sentido, imaginados, e no cenário diaspórico, esse sentido ganha uma nova complexidade, uma vez que a cultura modifica-se, portanto, os elementos simbólicos também são ressignificados. É por este viés, por exemplo, que podemos compreender que a comunidade árabe de Florianópolis se identifica como uma comunidade só, apesar de agregar pessoas de diferentes países do Oriente Médio, com culturas próprias.

Metodologicamente, a pesquisa está amparada na História Oral (THOMPSOM, 1992; POZZI, 2012), compreendendo que é possível fazer uma história do tempo presente com testemunhos orais, problematizando os discursos, o papel da memória e da narrativa. Para Pablo Pozzi (2012), ao pensar sobre a prática da História Oral, a mesma tem "[...] tentado não só o resgate da memória de setores antes marginalizados de seu protagonismo, mas também, o crescimento dos níveis de consciência desses como protagonistas desta história, e de uma realidade que pode ser modificada" (p. 63)². Nesse âmbito, foram realizadas entrevistas durante em diferentes momentos durante um período entre 2009 e 2016 e que são fontes centrais para delinear sujeitos e a constituição da comunidade árabe e muçulmana em Florianópolis.

\footnotetext{
2 Tradução livre do original: "[...] ha intentado no sólo el rescate de la memoria de sectores antes marginados en su protagonismo, sino también, el crecimiento de los niveles de conciencia de aquellos como protagonistas de esta historia, y de una realidad que puede ser modificada" (p. 63).
} 
Revista Brasileira de História \& Ciências Sociais - RBHCS

Vol. $8 \mathrm{~N}^{\mathrm{o}}$ 16, Julho - Dezembro de 2016

\section{(Trans)formação da comunidade árabe e muçulmana: algumas considerações}

Após o final da Segunda Guerra Mundial, a configuração mundial ficou alterada e novas dinâmicas e conflitos se estabeleceram. A imigração árabe ao Brasil e à Florianópolis também refletiram estas mudanças. Se no início do século XX a imigração árabe foi constituída por cristãos fugindo da perseguição em seus territórios3, a imigração pós-1945 é bastante diferente em termos de religião, país de origem, razões de emigração e formas de integração à sociedade brasileira.

A criação do Estado de Israel em 1948, em território até então palestino, provocou um desequilíbrio na geopolítica do Oriente Médio, esta que já se encontrava fragilizada pelos conflitos provenientes das independências de Síria e Líbano e inúmeras brigas por fronteira (CLEVELAND; BUNTON, 2009). Neste contexto, o êxodo da região passa a ser de árabes muçulmanos, principalmente da região da Palestina, em decorrência da contínua desterritorialização em detrimento do estado israelense. São os muçulmanos que agora passam a serem perseguidos e expulsos, buscando a migração como meio de sobrevivência.

Assim como aqueles que chegaram ao Brasil no início do século $\mathrm{XX}$, os imigrantes da segunda onda também escolheram o país baseados em questões econômicas por conta das possibilidades de trabalho no comércio e como mascates4. Esses imigrantes, além de buscarem proteção contra perseguição que sofriam em seus países de origem, também aspiravam encontrar no Brasil oportunidades e condições de trabalho que possibilitassem uma vida mais digna, não apenas para aqueles que chegaram ao Brasil para trabalhar mas também aos seus familiares que haviam ficado no Oriente Médio. Nesse aspecto, um elemento que compartilham com os imigrantes do início do século XX, segundo Espínola (2009), é a característica assimilacionista. Estes árabes imigrantes persistiram em absorver a cultura

3 O grande descolamento de imigrantes árabes cristãos ao Brasil se deu no fim do século XIX, aproximadamente a partir de 1870, inicialmente em São Paulo e em seguida redirecionados a outros locais, como Santa Catarina. Grande parte deste fluxo migratório, constituído em sua maioria por homens solteiros e agricultores, deveu-se às más condições de vida encontradas na Síria e no Líbano, como a falta de emprego e pobreza (PIAZZA, 2003). Além disso, neste período, o Império TurcoOtomano dominava a região e a perseguição aos cristãos era intensa e efetiva, fazendo com que o Brasil fosse um local propício para viver, onde encontrariam tolerância religiosa.

4 Tipo de comércio ambulante que vai de porta em porta levando toda espécie de artigos para vender nos lugares mais distintos. 
brasileira, buscando integração junto a sociedade e contribuindo para sua aceitação com a comunidade local.

Segundo informações obtidas de um de nossos entrevistados5, em 1988, havia cerca de vinte famílias de muçulmanos morando em Florianópolis que se reuniam informalmente durante a semana, embora não tenhamos informações mais específicas como sobrenomes e países de proveniência. Ainda assim, é importante notar que por conta da mudança no local de procedência dos imigrantes ocorreu também uma mudança no aspecto religioso da imigração que, até então, tinha se apresentado como predominantemente católica, sendo que a partir da segunda leva imigratória passam a ser majoritariamente muçulmanos. A interação entre esses dois grupos de origem semelhante era bastante limitada, segundo relatos de imigrantes da segunda geração, uma vez que em decorrência da diferença religiosa os espaços de sociabilidade dos grupos se tornaram bastante distintos. Não tendo a religião como um lugar, mesmo que virtual, de prática e trocas compartilhadas, a comunidade árabe muçulmana e a comunidade árabe cristã possuíam poucos pontos de contato. Os primeiros árabes em Florianópolis não criaram um espaço religioso em que o grupo se sociabilizasse de forma autônoma, como é bem lembrado por Liliane Carvalho (2002); ao contrário, ao chegarem a Florianópolis passaram a frequentar primeiramente a Igreja Católica, contribuindo para sua assimilação, como já mencionado anteriormente, e após outros lugares de sociabilidade da sociedade florianopolitana, como os clubes e os bares (CARVALHO, 2002).

Já os imigrantes árabes muçulmanos, no primeiro momento do seu estabelecimento na Ilha de Santa Catarina, segundo Espínola (2005), exerceram suas práticas culturais e sociabilidades "exclusivamente no espaço privado das casas" (p. 81). De acordo com a autora, a perspectiva destes imigrantes, uma vez que inauguravam um novo ciclo e com características culturais singulares, era de não chamarem muito atenção para as suas diferenças, no caso a religião, e se integrar ao conjunto da imigração árabe já existente e aceita pelos brasileiros. Esta tática de integração não implicou no abandono da crença e das práticas religiosas, apenas as confinou a suas dimensões privadas.

Sendo assim, começamos a perceber a organização e o estabelecimento de importante marcos para a permanência da comunidade na cidade. As primeiras e a

5 Entrevista realizada em 2010 com José (utilizado no pseudônimo, para preservar a identidade do entrevistado). 
segundas ondas não expressavam o desejo de estabelecer-se no Brasil, sendo este sempre visto como um lugar transitório, o local no qual se prosperaria e daria meios de voltar para os países de origem com mais capital. E dentro desta realidade começou-se a perceber elementos dentro da sociedade que indicavam para esta permanência

O Centro Islâmico foi formado inicialmente por um pequeno agrupamento de estudiosos da religião islâmica, curiosamente composto por três convertidos (dois brasileiros e um italiano) e três árabes. O grupo, em 1995, recebe o status de "utilidade pública" devido ao seu registro na prefeitura de Florianópolis, passando a ser denominado Núcleo de Estudos e Divulgação Corânica ${ }^{6}$. Sendo informalmente chamado de Centro Islâmico e/ou de Mesquita, o Núcleo de Estudos e Divulgação Corânica não teve em seu início, e ainda não tem, a configuração arquitetônica característica das mesquitas. Porém, o que antes não passava de uma simples Sala de Oração no Edifício Dias Velho, hoje ocupa o oitavo andar inteiro de um prédio da cidade, ambos localizados em uma das áreas mais movimentadas do comércio florianopolitano, no centro da cidade, fazendo referência tanto ao espaço físico, quanto à entidade, o local atual do Núcleo. Além das atividades religiosas realizadas com frequência, principalmente às sextas-feiras quando a presença dos homens é obrigatória segundo o Alcorão, o espaço também abriga outras atividades como local de reuniões, de ensino da língua árabe, de comemorações do mês do Ramadã. Desta forma, exercendo, em geral, a função de ambiente de referência e contato tanto com a comunidade árabe muçulmana de Florianópolis7 como com a religião muçulmana e a cultura árabe.

Nesse sentido, a criação do Núcleo de Estudos e Divulgação Corânica representou, para além do caráter oficial, uma das primeiras manifestações significativas - se não a primeira - da comunidade muçulmana florianopolitana reconhecida coletivamente. Devido à constituição do Centro Islâmico, a população árabe muçulmana da capital catarinense projeta-se enfim, de maneira até então não observada, na esfera pública da cidade, mesmo que esse não tenha sido um dos seus objetivos. Instituído um espaço comum e público para as práticas e estudos religiosos muçulmanos, a comunidade árabe muçulmana se vê, por fim, incitada a estabelecer

\footnotetext{
${ }^{6}$ Foi registrado assim na prefeitura como utilidade pública no dia 24/07/1995, passando a possuir então caráter de sociedade jurídica, estatuto próprio e diretoria legitimada através de eleições.

7 Também recebendo muçulmanos de outras localidades.
} 
Revista Brasileira de História \& Ciências Sociais - RBHCS

Vol. $8 \mathrm{~N}^{\mathrm{o}}$ 16, Julho - Dezembro de 2016

contato com os convertidos não-árabes, brasileiros e demais estrangeiros, possibilitando dessa maneira uma maior interação entre os grupos muçulmanos da cidade (ESPÍNOLA, 2009).

A partir da criação da Mesquita, pode-se observar que, até os dias atuais, houve uma gradativa acentuação da participação e visibilidade dos imigrantes árabes na cidade de Florianópolis. Outros elementos corroboram com esta hipótese, como a vinda do Sheikh Amin Alkaram, em 2001, contribuindo para uma organização comunitária e espiritual da comunidade árabe muçulmana na capital catarinense. Também, a criação do Comitê Catarinense de Solidariedade ao Povo Palestino, criado em 2003 e vinculado a políticas de esquerda, tem como objetivo difundir a causa palestina e promover ações de solidariedade a refugiados. O grupo promove palestras e encontros que são abertos a todos, assim como o próprio comitê. Por iniciativa do comitê foram realizadas passeatas em nome de uma palestina livre, contando com palestinos, árabes e brasileiros. Uma grande vitória em nome da causa foi a instituição do dia 29 de novembro como o Dia Municipal de Solidariedade ao Povo Palestino, por meio da Lei Municipal No $3440 / 90$ e a Lei Estadual № 13.850/2006. Por meio dessa organização, observa-se a participação política de membros da comunidade árabe, da visibilidade de palestinos na cidade e a agenda da Questão Palestina (referido ao litígio territorial e seus desdobramentos) no cenário de Florianópolis.

Ainda em decorrência da organização resultante da criação do Centro Islâmico, que passa a ser um local de articulação política, é criado, dentro do cemitério municipal da cidade de Florianópolis, em 2002, de um cemitério nos moldes islâmicos. Possuindo lugar para 200 corpos, o local é separado do restante do cemitério por um muro e portão. De acordo com os integrantes da comunidade, a conquista de um espaço para realização de enterros e funerais aos moldes da religião islâmica foi negociada juntamente as autoridades e teve um efeito bastante relevante para a comunidade. Nesse sentido, a concessão de um terreno no cemitério municipal de Florianópolis, para o enterro de árabes muçulmanos de acordo com a tradição islâmica, mostra um processo mais próximo do enraizamento na cidade, para além de lugar de passagem para os imigrantes e descendentes, pertencentes às levas imigratórias mais recentes, mas antes, um lugar de vivência e estabelecimento. A criação do cemitério também possibilitou que diversas pessoas de religião 
muçulmana, árabes e convertidos, pudessem trazer os corpos de seus entes queridos enterrados em outros locais, e até em outras cidades, para um local que seguia suas tradições. A possibilidade de exercerem sua religião de diversas formas proporciona um sentimento de maior aceitação dos imigrantes junto a comunidade local.

Essa fase, descrita acima, de criação de espaços de prática de religiosidade e cultura, tem início em 1995 - tomando-se a criação do Centro Islâmico como período inicial - e acompanha a mudança entre as características dos imigrantes árabes em Florianópolis. Considera-se que houve o início de uma terceira onda de imigração árabe, que é caracterizado por uma continuidade com a segunda onda, quanto a proveniência e religiosidade dos indivíduos migrantes, sendo que a transformação da comunidade se dá mais especificamente nas relações sociais estabelecidas internamente, com solidificação de redes de parentesco, por exemplo, e principalmente externamente, com a construção de espaços visíveis a serem praticados na cidade.

Nesta onda de imigração percebemos dois períodos distintos que não implicam em ondas divergentes, mas que têm características específicas distintas. Assim, preferimos falar da primeira fase da terceira onda, como sendo aquela marcada por um contingente populacional com características de proveniência similar às características da segunda onda mas mais jovem e com o advento de refugiados palestinos, ao passo que a segunda fase da terceira onda, iniciada em 2011, observa o incremento populacional influenciado pela guerra civil na Síria, implicando no aumento do número de refugiados em Florianópolis.

A comunidade árabe muçulmana em Florianópolis, em 2010, era composta por, aproximadamente, 60 famílias, cerca de 300 pessoas segundo o Sheikh da Mesquita de Florianópolis, Amin Alkaram. Embora não exista registro formal e institucionalizado por parte da comunidade sobre os indivíduos que a compõem, há o estabelecimento de uma estimativa; parte da justificativa para a dificuldade do mapeamento completo dessas famílias e indivíduos se dá pelo fato da constante movimentação da comunidade e da dificuldade de órgãos oficiais em satisfatoriamente levantarem dados migratórios. Atualmente, estima-se que o número de refugiados sírios chegados à cidade desde 2011 seja de 100 pessoas.

A característica predominante da nova imigração se deve especialmente à aceleração dos meios de transporte e de comunicação percebidos na 
contemporaneidade, que proporcionam, entre outras coisas, a possibilidade de se vivenciar a "família ampliada”. Cunhada por Stuart Hall (2006), a expressão "família ampliada” ilustra de maneira eficaz a experiência vivida por esses novos imigrantes que ao partirem de seus países de origem nunca os deixam inteiramente, vivenciando uma dimensão transnacional, fruto do tempo presente, que se apoia, entre outros elementos, no núcleo familiar expandido geograficamente. Esta dimensão apontada por Hall é percebida na prática da comunidade árabe em Florianópolis, uma vez que, desde a segunda onda migracional, a possibilidade de viver em dois lugares torna-se uma característica desses migrantes (ESPÍNOLA, 2009). Dessa maneira, trabalhadores, comerciantes e profissionais liberais que não possuem a disponibilidade de se ausentarem por longas temporadas fazem viagens constantes. Através destas são feitas aproximações com o país de origem, diminuindo as distâncias e tornando possível "a experiência de estar aqui e estar lá” (ESPÍNOLA, 2009, p. 109)

Um aspecto presente ao entrevistarmos os imigrantes, especificamente muçulmanos, é a ideia de direito ao retorno, e uma reivindicação política específica para os palestinos em diáspora. Diversas vezes durante as entrevistas com os imigrantes, nos foi apresentada a ideia de Florianópolis, e do Brasil, como um local de passagem e não como um novo local para viver permanentemente. São buscados com a imigração, meios e condições de melhorar a vida dos familiares que permaneceram nos locais de origem, e não de trazerem todos os familiares para cá. Alguns dos imigrantes árabes com os quais tivemos contato pretendem trabalhar e acumular capital para, assim, voltarem aos seus países de origem com melhores condições. O vínculo mantido pelos imigrantes com os locais de origem é marcadamente forte, característico do transnacionalismo que caracteriza muitos processos migratórios. Os filhos, nascidos no Brasil, são mandados para, juntamente com os familiares que permaneceram no lugar emigrado, conhecer a cultura e aprender a língua da família. Muitos jovens nascem no Brasil e passam boa parte da infância e da juventude em países como o Líbano e a Jordânia, regressando ao Brasil muitas vezes sem falar o idioma português:

A intenção é claramente fortalecer a tradição e a identidade do grupo assegurando uma continuidade dos costumes e d cultura de origem nas novas gerações. Viajar ou morar temporariamente no país de onde vieram seus ancestrais para a 
segunda e mesmo para a terceira geração é uma forma de manter os laços familiares e a tradição, mesmo longe, num novo país com costumes tão diversos (SOARES, 2008, p. 68).

Além do contato direto com a cultura original através das viagens, a perpetuação e manutenção do legado cultural e étnico, é alcançada principalmente pela constituição familiar. Dentro da tradição muçulmana, os casamentos não são necessariamente inter-étnicos e há a possibilidade de homens casarem com mulheres não muçulmanas. Como o grupo e árabes muçulmanos em Florianópolis se encontra em uma situação diferente e delicada, devido a migração, o número de casamentos com mulheres brasileiras é reduzido. A maioria dos homens retorna ao país de origem para encontrar uma companheira, sendo que esta, provavelmente, já foi escolhida pela base familiar no país. A família, principalmente as mulheres mais velhas, possuem essa função de articular os casamentos dentro da comunidade. Com o casamento, pretende-se, segundo os imigrantes, manter-se mais tempo ligado aos costumes e língua de origem, pois a mulher é tida como aquela que irá perpetuar a tradição e os costumes étnicos e religiosos.

Esta terceira onda migracional, colocou em pauta um problema "tão antigo quanto a própria humanidade": os refugiados, ao qual consideramos ser um ponto específico desta atual onda migratória para Florianópolis. Desde 1999, quando o governo brasileiro assinou um acordo com a Organização das Nações Unidas para se transformar em local de reassentamento oficial de refugiados, o país vem recebendo frequentemente "os mais vulneráveis entre os vulneráveis". Ao reconhecer o status de refugiado, o estado brasileiro, em 2007, recebeu mais de 100 palestinos que estavam em campos de refugiados. Um deles, após ir para Mogi das Cruzes/SP, foi convidado pela comunidade muçulmana de Florianópolis a ministrar aulas de língua árabe na Mesquita da cidade e se tornou o primeiro refugiado árabe na comunidade. No entanto, após 2011 este panorama mudou drasticamente. Tem início o que chamamos de segunda fase da terceira onda, na tentativa de explorar melhor as singularidades das pessoas refugiadas sírias que chegaram em Florianópolis a partir de 2011.

Assim, a terceira onda observa na primeira fase uma mudança com a criação de espaços para as sociabilidades culturais e islâmicas da comunidade, com a tardia criação de um Centro Islâmico e mesquita em Florianópolis, ao mesmo tempo que observa a chegada de refugiados palestinos. Em 2011 teve início a guerra civil na Síria, o embate entre as forças contrárias e apoiadoras ao presidente sírio Bashar al- 
Assad já foi responsável por mais 300 mil fatalidades e o pungente número de 4.5 milhões de refugiados sírios.

Com o início da guerra civil na Síria, estima-se, em 2016, que o número de pessoas forçadas a saírem de suas casas é superior a 11 milhões, sendo que destes 4,5 buscaram refúgio em outros países (BBC, 2016). Desde 2011, segundo dados do CONARE (Comitê Nacional para Refugiados), mais de 2,2 mil refugiados chegaram ao Brasil. Antes do início do conflito, menos de 20 refugiados sírios se encontravam no Brasil e hoje os sírios já formam o maior grupo de refugiados no Brasil, país que tem mais de 8.000 refugiados. Percebendo o intensificação do conflito no país do Oriente Médio, em 2013, o Brasil adotou uma Resolução Normativa ${ }^{8}$ que desburocratiza o processo ao legalizar a emissão de um visto de turista por 90 dias para facilitar a entrada no Brasil a quem queria solicitar refúgio, sírios e demais estrangeiros afetados pela guerra civil. Desta forma, o Brasil se transformou no país da América Latina que mais facilita a chegada dos sírios, sendo assim também o que mais recebe refugiados sírios no continente.

Desta feita, muitos refugiados ao chegarem no país buscam pelas redes já estabelecidas entre os imigrantes, das ondas anteriores, procurando comunidades árabes muçulmanas ou cristãs já consolidadas. Florianópolis insere-se neste circuito e desde 2011, mais de 100 refugiados passaram a buscar proteção e acolhimento na capital catarinense, elegendo a cidade como destino final pelas quais chegaram os árabes de outras ondas9.

Os refugiados sírios que chegaram à Florianópolis são em sua maioria homens, solteiros, jovens, tendo a comunidade menos de 20 mulheres e 12 crianças. Essa comunidade de recém chegados à Florianópolis é preponderantemente da mesma região síria, da capital Damasco, tendo sido afetados pela guerra e com envolvimentos no conflito de diferentes formas. A temática da guerra, ainda que permeie as vivências de todos eles/as, não é um assunto debatido quando em segurança no Brasil.

\footnotetext{
8 Resolução Normativa CONARE No 17 DE 20/09/2013

9 Um levantamento de dados importantes foi realizado pela GAIRF (Grupo de Apoio as Imigrantes e Refugiados de Florianópolis e Região) em 2015, divulgando informações acerca da proveniência e motivos da migração de indivíduos de vários lugares do mundo. Neste levantamento também há informações sobre a imigração árabe contemporânea.
} 
Diferentemente de outros imigrantes da mesma onda migratória, os refugiados sírios não possuem qualquer desejo de retornar ao seu país de origem, principalmente por conta da própria condição do refugiado. Segundo Cairus (2015):

O refugiado sírio, em geral, tem São Paulo como primeiro "porto de chamada" no Brasil, mas como as comunidades muçulmanas são, muitas vezes, articuladas em vários níveis entre si (no caso Florianópolis é ligada a "matriz ideológica" localizada em São Bernardo do Campo e ao Rio de Janeiro, este último inclusive por vínculos de parentela), Florianópolis torna-se incialmente um destino sugerido e depois, como ocorre em fenômenos migratórios, passa a ser promovido pelos próprios imigrantes ${ }^{10}$.

A integração dos refugiados à sociedade perpassa a existência da mesquita como local de orações e de sociabilidades. São os imigrantes chegados anteriormente e já estabelecidos que abrem as portas para a integração social e laboral. Ainda que a população de refugiados seja diversificada - muitos são de famílias tradicionais, com profissões como advocacia e agricultura - no Brasil desempenham atividades, principalmente, no comércio e em restaurantes, quase sempre a partir de oportunidades proporcionadas por outros imigrantes.

Ainda que tenha havido importante recepção por parte dos imigrantes árabes muçulmanos em Florianópolis, os refugiados sírios que buscam recomeçar suas vidas na capital de Santa Catarina ainda enfrentam significativos obstáculos. Para além do precário acesso ao mercado de trabalho, favorecido apenas pela própria comunidade, a educação das crianças e adolescentes e a inserção das mulheres no mercado de trabalho são dificultadas pela ausência de políticas públicas de integração e orientação a imigrantes e refugiados. Apesar de terem acesso à saúde pública garantida, os refugiados possuem grande dificuldade de comunicação com médicos e enfermeiros da rede pública de saúde.

Concomitante à chegada dos refugiados, outros grupos passaram a frequentar o Centro Islâmico e contribuíram para o grande crescimento do mesmo. Segundo Cairus (2015), houve um movimento migratório interno na qual famílias árabes se reestabeleceram em Florianópolis vindas de outras cidades do estado de Santa Catarina. Estas famílias buscaram esta mudança por Florianópolis ser uma cidade em expansão econômica e a comunidade árabe muçulmana já estar bastante consolidada.

Outro grupo que se soma ao crescimento da comunidade frequentadora ao Centro Islâmico de Florianópolis é o de imigrantes não-árabes, mais especificamente

10 Entrevista realizada em 2015. 


\section{Revista Brasileira de História \& Ciências Sociais - RBHCS}

Vol. $8 \mathrm{~N}^{\mathrm{o}}$ 16, Julho - Dezembro de 2016

ganeses e senegaleses. Nos últimos anos, principalmente após 2014, imigrantes e refugiados provenientes de países africanos buscaram melhores condições no Brasil e por proximidade religiosa envolveram-se com as comunidades árabes muçulmanas. Este é um eixo de estudo fundamental para compreender os deslocamentos atuais e as relações estabelecidas entre comunidades em cidades como Florianópolis. Infelizmente, não tivemos contato com esses indivíduos, mas são apontados aqui como potencialmente importantes para a modificação das estruturas espaciais muçulmanas, podendo inclusive contribuir com uma des-arabização da mesquita e de outros espaços. Não há estudos que comprovem esta hipótese, mas abrimos esta problemática como uma possibilidade de estudo futuro.

Em Florianópolis, esses novos grupos que participam da comunidade árabe fizeram com que o Centro Islâmico, importante espaço de sociabilidade da comunidade, não a comporte mais, segundo Cairus (2015): "Por isso, refletindo este fenômeno, está sendo construído um complexo, com mesquita e madrasa (escola) em Coqueiros [bairro da cidade]". E continua, ao constatar que é nas celebrações coletivas de datas festivas que participou, "nas quais é possível observar a dimensão real da comunidade muçulmana em Florianópolis"11. Este dado igualmente aponta para uma crescente e próspera consolidação das comunidades árabe e não-árabe muçulmanas na capital catarinense, cuja constituição histórica é rica e relevante para a compreensão das dinâmicas sociais, raciais e étnicas na cidade.

\section{Considerações Finais}

Este artigo procurou identificar as relações de aproximação e distanciamento entre os processos migratórios árabes e/ou muçulmanos para Florianópolis/SC. Com enfoque a partir da década de 1990, foi possível constatar um aumento significativo da comunidade árabe e muçulmana na cidade, a partir de dados obtidos em entrevistas, bem como através do aumento dos espaços praticados pelos mesmos, como a Mesquita e Centro Islâmico. Ainda nesta ambiência, é possível inferir que houve uma mudança quanto ao uso desses espaços, passando de uma esfera privada para, cada vez mais, uma esfera pública, ou seja, atualmente há uma publicidade

${ }^{11}$ Idem. 


\section{Revista Brasileira de História \& Ciências Sociais - RBHCS}

Vol. $8 \mathrm{~N}^{\mathrm{o}}$ 16, Julho - Dezembro de 2016

maior e mais direta e em congruência com o fluxo da cidade, agora integrada por outras populações praticantes do islamismo. Esta constatação permite o levantamento de duas questões de âmbitos gerais: primeiramente, uma possível e gradativa desvinculação do elemento árabe na comunidade muçulmana, ainda que isso deva ser problematizado com cautela, visto que a presença de um sheikh árabe, por exemplo, pode contribuir para as permanências culturais na mesquita; e segundo, analisar como estes novos fluxos migracionais, principalmente com os refugiados sírios e de origem africana alteraram a forma de relação com a comunidade em Florianópolis, entre si e perante aos tantos 'outros' moradores na capital.

Em relação à computação de dados estatísticos, entendemos como necessário e fundamental mais estudos sobre a temática, a fim de angariar informações que potencialmente podem servir como uma base de dados para melhor compreender a formação da comunidade árabe e muçulmana em Florianópolis em uma perspectiva histórica. Outra questão necessária de se considerar, e já apontada a partir de uma entrevista realizada citada, é o fato do fluxo migratório ser extremamente fluído na contemporaneidadee, portanto, mais difícil de delimitar os "de fato" pertencentes à comunidade. Apesar das redes de parentesco, muitos árabes vindos do Oriente Médio são solteiros e não pertencem necessariamente à alguma família, dificultando também o registro.

Por último, as novas dinâmicas de imigração acarretaram em uma nova forma de interação com a cidade e com a transitoriedade, ou não, do projeto migratório. A chegada de refugiados, sírios e palestinos, impõe novas experiências migratórias à dinâmica da cidade, com desafios inerentes. A limitação da língua é amenizada pelo acolhimento que os refugiados recebem de outras pessoas da comunidade árabe muçulmana. No entanto, é ainda um fluxo recente que depreenderá estudo e observação nos próximos anos. 


\section{Referências}

Entrevistas:

Entrevista concedida por José (pseudônimo) a AUTORA e Bruno Bortoli (2010).

Entrevista concedida por João (pseudônimo) a Bruno Bortoli e Emerson César de Campos (2010). O material desta entrevista foi cedido pelos entrevistadores às autoras deste artigo.

Entrevista concedida por Tufy Cairus a AUTORA (2015).

Entrevista concedida pelo Sheikh Amin Alkaram a Bruno Bortoli (2010). O material desta entrevista foi cedido pelos entrevistadores às autoras deste artigo.

Bibliografia:

ANDERSON, Benedict. Comunidades Imaginadas: reflexões sobre a origem e a difusão do nacionalismo. São Paulo: Ed. 70, 2005.

BHABHA, Homi K. O local da cultura. Belo Horizonte: Ed. da UFMG 1998.

BOABAID, José Felipe. A Contribuição Sírio-Libanesa. In: MELLO, Oswaldo F. de. História sócio-cultural de Florianópolis. Florianópolis: Lunardelli/IHGSC, 1991.

BRITISH BROADCAST CORPORATION- BBC. Syria: the story of the conflict. 11 mar 2016. Disponível em: <http://www.bbc.com/news/world-middle-east-26116868>. Acesso em: 06 ago 2016.

BRUTLEIN, V.; WANIEZ, P. Os muçulmanos no Brasil: elementos para uma geografia social. ALCEU. V. 1, n. 2, pp. 155-180, 2001.

CABRAL, Oswaldo Rodrigues. Nossa Senhora do Desterro. v. 1 Notícias. Florianópolis: Lunardelli, 1979.

BORTOLI, Bruno; AUTORA; LISBOA, Catarina; AUTORA. De Camponeses à Comerciantes: Reflexões sobre a Imigração Árabe em Florianópolis (1990-2010). Florianópolis no Tempo Presente. Editora da UDESC e DIOESC, 2010.

CARVALHO, Liliane. Do Balcão à mesa: Imigrantes de descendentes de sírios e libaneses na construção de uma identidade na Grande Florianópolis (1910-1950). Universidade Federal de Santa Catarina, 149 p. Dissertação (mestrado) - PósGraduação em História, Centro de Filosofia e Ciências Humanas, Florianópolis, 2002.

CORREIA, Mariana Knierim. Entre este e aquele: as uniões matrimoniais entre os muçulmanos residentes em Florianópolis- SC. Florianópolis: UFSC, 2010 (Trabalho de Conclusão de Curso de Ciências Sociais) 
ESPINOLA, Claudia Voigt. O véu que (des)cobre: etnografia da comunidade árabe muçulmana em Florianópolis. Universidade Federal de Santa Catarina, 244 p. Tese (doutorado) - Antropologia Social, Centro de Filosofia e Ciências Humana, Florianópolis, 2005.

GATTAZ, André. Do Líbano ao Brasil: história oral de imigrantes. $2^{\mathrm{a}}$ edição. Salvador: Editora Pontocom, 2012.

Grupo de Apoio ao Imigrante e Refugiado de Florianópolis e Região (GAIRF). Novos Imigrantes e Refugiados na Região da Grande Florianópolis: Observações preliminares sobre suas experiências e demandas. Florianópolis, 2015.

HALL, Stuart. A identidade cultural na pós-modernidade. Rio de Janeiro: DP\&A, 2006.

- Da Diáspora: Identidades e Mediações Culturais. 1a edição atualizada. Belo Horizonte: Ed. UFMG, 2009.

KLUG, João. Imigração e Luteranismo em Santa Catarina - A Comunidade Alemã de Destero/Florianópolis. Florianópolis: Papa-Livro, 1994.

MOTT, M.L. Imigração árabe: um certo orienta no Brasil. In: INSTITUTO BRASILEIRO DE GEOGRAFIA E ESTATÍSTICA. Brasil: 500 anos de povoamento. Rio de Janeiro, 2000. Disponível em: < http://brasil50oanos.ibge.gov.br/territoriobrasileiro-e-povoamento/arabes $>$. Acesso em setembro de 2015.

PIAZZA, Walter Fernando, HÜBENER, Laura Machado. Santa Catarina: história da gente. Florianópolis: Lunardelli, 2003 (6 $6^{\mathrm{a}}$ edição).

PIAZZA, Walter Fernando. A colonização de Santa Catarina. Florianópolis: Lunardelli, 1982.

POZZI, Pablo. Esencia Y Practica de La Historia Oral. Tempo e Argumento: Revista do Programa de Pós-Graduação em História. Florianópolis, v. 4, n. 1, p. 61-70, jan.jun. 2012.

SEYFERTH, Giralda. Imigrantes, estrangeiros: a trajetória de uma categoria incômoda no campo político. $26^{a}$ Reunião Brasileira de Antropologia, realizada entre os dias 01 e 04 de junho de 2008. Porto Seguro, Brasil. Disponível em: < http://www.abant.org.br/conteudo/ANAIS/CD_Virtual_26_RBA/mesas_redondas/ trabalhos/MR\%2012/giralda\%20seyferth.pdf>. Acesso: set./2015.

SOARES, Gabriel Mathias. Da Palestina ao Brasil: Identidade e imigração palestina em Florianópolis (1967-2007). Florianópolis: UFSC, 2008 (Trabalho de Conclusão de Curso de História)

THOMÉ, Leonardo Leite. Refugiados sírios em Floripa. Disponível em: $<$ http://oestrangeiro.org/2014/o5/28/refugiados-sirios-em-floripa/>. Acesso em setembro 2015 . 
Revista Brasileira de História \& Ciências Sociais - RBHCS

Vol. $8 \mathrm{~N}^{\mathrm{O}}$ 16, Julho - Dezembro de 2016

THOMPSON, Paul Richard. A voz do passado: história oral. São Paulo: Paz e Terra, 1992.

Recebido em Agosto de 2016 Aprovado em Setembro de 2016 